\title{
THE DEVELOPMENT OF VITAMIN K AND ITS CLINICAL USES IN THE NEONATAL PERIOD
}

\author{
BY \\ HOWARD SAVAGE, M.D.
}

Within recent years the paediatrician has gained many synthetic therapeutic aids. These include sulphanilamide and allied compounds, various members of the vitamin $B$ complex, the anti-convulsant dilantin, and in addition an anti-haemorrhagic agent which has been called vitamin $K$.

It is eleven years since Dam $(1929,1930)$, of the University of Copenhagen staff, attempted to determine if cholesterol could be produced in newly hatched chicks on a cholesterol-free diet from which the fats and allied compounds had been removed by ether extraction. He found that within a few weeks the chicks succumbed to severe haemorrhages from the skin and gastro-intestinal tract. To the absent anti-haemorrhagic factor he gave the name 'Koagulationsvitamin' or, as it came to be called, vitamin K. Dam further showed (1935) that this fat-soluble substance was widely distributed in nature, alfalfa, tomatoes and hog liver oil being effective in supplying the deficiency, alfalfa being the best source.

Although this anti-haemorrhagic factor in the normal diet of young chicks was postulated in 1929, it was not until seven years later that Schonheyder (1936), also of the University of Copenhagen staff, demonstrated a deficiency of prothrombin in the plasma of chicks on a vitamin $\mathrm{K}$-free diet. The addition of vitamin $\mathrm{K}$ to their diet was followed not only by a rapid cure of their haemorrhagic tendency but also by a coincident rise of their plasma prothrombin to a normal value.

The clinical application of this research lies in those conditions in which there is a reduced amount of prothrombin in the circulating blood. A normal blood prothrombin is described by Butt, Snell, and Osterberg (1939a) as dependent on four factors: (1) there must be adequate amounts of vitamin $\mathrm{K}$ in the diet; (2) there must be adequate amounts of bile salts in the small bowel to render the vitamin $\mathrm{K}$ soluble; (3) there must be a normal intestinal absorptive surface, through which the dissolved vitamin $\mathrm{K}$ may be absorbed, and ensure that the vitamin $K$ does enter the portal circulation or the intestinal lacteals; and (4) there must be a physiologically normal liver, to employ the vitamin $K$ in the production of prothrombin.

On this basis, then, a haemorrhagic tendency occurring in cases of obstructive jaundice is due to lack of bile salts in the bowel, often coupled with a malfunctioning cirrhotic liver. In some cases of coeliac disease in children (Fanconi, 
1938), and in idiopathic steatorrhoea or sprue in adults (Clark et al., 1939), a reduced prothrombin content has been found, and is believed to be due to failure of the intestinal mucosa to absorb fats and fat-soluble substances, including vitamin $\mathrm{K}$. In farming communities it is common knowledge that the dehorning of cattle pasturing on sweet clover is often followed by prolonged and sometimes fatal haemorrhage from the dehorning site; cattle fed on partly spoiled sweet clover hay have a reduced prothrombin plasma content, presumably due to a mal-functioning liver damaged by toxins liberated by intestinal fermentation of this feed (Roderick, 1931).

The hypoprothrombinaemia of new-born infants is of greatest interest to paediatricians, as the basis of neonatal haemorrhagic disease. Several investigators (Quick and Grossman, 1939; Bray and Kelley, 1940) during the past twelve months have shown that following birth there is a physiological decrease in the prothrombin content of the blood, with a subsequent spontaneous restoration to normal values. This is complete by the fourth day of life when the decrease has been small, or by the sixth day when there has been marked reduction. It is in those cases in which prothrombin decrease has been greatest and prothrombin restoration takes longest that the severe spontaneous haemorrhages, recognized clinically as haemorrhagic disease of new-born, occur.

The cause of this deficiency is suggested by Quick and Grossman (1940) to be due to an inadequate storage of prothrombin or of vitamin $\mathrm{K}$ in the foetus. Presumably as soon as the baby is born the physiological demands promptly exhaust the available prothrombin, and since there is apparently neither a reserve of this substance nor of vitamin $\mathrm{K}$ a marked decrease of prothrombin occurs. Milk, a poor source of vitamin $\mathrm{K}$, provides little help. The liver of the new-born infant is only able to secrete small amounts of bile (Marriott, 1935), so that the capacity of these infants to absorb fats is limited. Another factor is the hypermotility of the gastro-intestinal tract during the first week of life. The greatest source of vitamin $\mathrm{K}$ during the first few days of life would appear to be its synthesis by bacteria introduced into the intestinal tract following birth; considerable amounts of vitamin $\mathrm{K}$ have been shown (Almquist et al., 1938) to be present in pure cultures of staphylococcus aureus, bacillus coli, bacillus cereus, bacillus subtilis, and the tubercle bacillus, of which mention will be made later.

Numerous reports as to the efficacy of vitamin $\mathrm{K}$ preparations, producing a sharp reduction of the prothrombin time and simultaneous cessation of haemorrhage in cases of neonatal haemorrhagic disease, have been forthcoming during the past fourteen months, in March, 1939, from Waddell, Guerry, Bray, and Kelley of Virginia, and in December, 1939, from Dam, Tage-Hansen, and Plum, of Copenhagen. As an example, the Virginia workers reported the cases of two infants, both four days old; one had a greatly prolonged prothrombin time of 420 seconds, and the other one of 210 seconds. To both infants 2 c.c. of a concentrate rich in vitamin $K$ were given by mouth, and in both instances there was reduction of their prothrombin times to almost normal values in two hours.

Such a report answers the criticism of the doubtful effectiveness of vitamin $\mathrm{K}$, based on the self-limiting nature of haemorrhagic disease of the 
new-born. Bray and Kelley (1940) showed that the return of the prothrombin level to normal in the natural course of events is a gradual process, extending over twenty-four to seventy-two hours, depending on the extent of the previous prothrombin fall, whereas, following vitamin $\mathrm{K}$ administration, the prothrombin restoration to normal is extremely rapid (Waddell et al., 1939; Snelling, 1940), over a period of two to four hours.

While interest in the possibilities of vitamin $\mathrm{K}$ was being aroused in various clinics, Almquist and Klose (1939a) announced that a synthetic substance, phthiocol, had definite curative effects on chicks on a vitamin $\mathrm{K}$-free diet. Phthiocol was first isolated from cultures of tubercle bacilli (Anderson and Newman, 1933a), later synthesized, and shown (1933b) to belong to a group of organic compounds called naphthoquinones. The starting-point of the studies that linked up the naphthoquinones and natural vitamin $\mathrm{K}$ was work by Dam (1939) showing that certain naphthoquinones and natural vitamin $K$ had identical ultra-violet absorption spectra.

A variety of naphthoquinones has been found to be effective in curing haemorrhagic disease in chicks (Ansbacher and Fernholz, 1939; Almquist and Klose, 1939b), but the most active and least toxic one has been shown to be 2-methyl-1,4-naphthoquinone, a single dose of 1 milligramme orally, intramuscularly or intravenously being sufficient to cure this disease effectively and rapidly. The honour of being the first to use the naphthoquinone, phthiocol, with clinical success goes to a group of Iowa City workers, Smith, Ziffren, Owen, and Hoffman (1939), who reported giving phthiocol intravenously to a case of obstructive jaundice with good results. This work has been confirmed subsequently by the same workers and also by Butt, Snell, and Osterberg (1939b).

The first report of the use of methyl naphthoquinone in neonatal haemorrhagic disease was by Nygaard (1939), who gave 5 milligrammes intramuscularly with 5 milligrammes by mouth, normal prothrombin values resulting in ten to twenty-four hours. Rhoads and Fliegelman (1940) reported the use of this drug given in 1-milligramme doses orally to new-born infants with haemorrhagic tendency, with similar results. More recently the intramuscular injection of $\frac{1}{3}$ to 1 milligramme of methyl naphthoquinone dissolved in corn oil was reported by Andrus and Lord (1940), with prompt response of prothrombin levels. The efficacy of this substance in actual neonatal haemorrhagic disease has been further demonstrated (Snelling, 1940) by work done at the Hospital for Sick Children, Toronto, during the past three and a half months.

In addition to the use of vitamin $\mathrm{K}$ preparations therapeutically, the use of vitamin $\mathrm{K}$ prophylactically should prove of increasing importance in the hands of paediatricians. In its prenatal use it has been reported by Hellmann and Shettles (1939) that the daily administration of 3100 Ansbacher units to two mothers for sixteen and thirty days before delivery not only doubled the maternal blood prothrombin content at delivery but tripled the prothrombin content of the infants ${ }^{\circ}$ umbilical cord blood. Moreover, these same workers showed that about fifty per cent. of infants born prematurely had blood prothrombin levels so low as to be within the range reported for haemorrhagic disease. It is only necessary to recall the considerable incidence of fatal 
cerebral haemorrhage in premature infants to realize the prophylactic potentialities of this anti-haemorrhagic agent when given prenatally.

In the neonatal period vitamin $K$ therapy should be of real value. The frequent appearance of symptoms of intracranial haemorrhage on or about the third day of life, when correlated with the period of greatest reduction of prothrombin values, is disturbing. A suggested explanation (Grossman, 1940) is that minor injuries to intracranial blood vessels during delivery permit slow oozing to continue, owing to the faulty blood clotting mechanism, and since this mechanism becomes increasingly inefficient during the first three days of life, it is on or about the end of that time that the dread and often fulminating symptoms of intracranial haemorrhage appear. Waddell and Guerry (1939) therefore suggest a real indication for the oral administration of vitamin $\mathrm{K}$, advising that 1 c.c. of a vitamin $K$ concentrate be given at the end of the first twenty-four hours of life, $\frac{1}{2}$ c.c. at the end of the first forty-eight hours, and a second $\frac{1}{2}$ c.c. at the end of the first seventy-two hours, especially to prematurely born infants.

A further indication for its prophylactic use is preoperatively, when any surgical intervention is found necessary during the first week of life, so that any undue bleeding due to a low prothrombin level may be avoided.

In conclusion, it may be hoped that, by means of this new drug, methyl naphthoquinone, it will become possible not only to cure neonatal haemorrhagic disease but to place this disease in the group of preventable disease along with rickets, scurvy, diphtheria, and tetanus.

\section{REFERENCES}

Almquist, H. J., Pentler, C. F., and Mecchi, E. (1938). Proc. Soc. exp. Biol., N.Y., 38, 336.

, and Klose, A. A. (1939a). J. Amer. chem. Soc., 61, 1611.

- (1939b) Loc. cit., 1923.

Anderson, R. J., and Newman, M.S. (1933a). J. biol. Chem., 101, 773.

An, (1933b). Ibid., 103, 197 .

Andrus, W. D., and Lord, J. W. (1940). J. Amer. med. Ass., 114, 1336.

Ansbacher, S., and Fernholy, E. (1939). J. Amer. chem. Soc., 61, 1924.

Brav, W. E., and Kelley, O. R. (1940). Amer. J. clin. Path., 10, 154.

Butt, H. R., Snell, A. M., and Osterberg, A. M. (1939a). J. Amer. med. Ass., 113, 383.

(1939b). Proc. Maio Clin., 14. 497.

Clark, R. L., Dixon, C. F., Butt, H. R., and Snell, A. M. (1939). Loc. cit., 407.

Dam, H. (1929). Biochem. Z., 215, 475.

- (1930). Ibid., 220, 158.

- (1935). Nature, 135, 652.

Tage-Hansen, E., and Plum, P. (1939). Luncet, 2, 1157.

, et al. (1939). Helv. chim. Acta, 22, 310.

Fanconi, G. (1938). Dtsch. med. Wschr.. 64, 1565.

Grossmann, A. M. (1940). J. Pediat., 16, 239.

Hellmann, L. M., and Shettles, L. B. (1939). Johns Hopk. Hosp. Bull., 65, 138.

Marriott, W. M. (1935). Infant nutrition, second edition. St. Louis.

Nygaard, K. K. (1939). Acta obstet. glnec. scand., 19, 361.

Quick, A. J., and Grossmann, A. M. (1939). Proc. Soc. exp. Biol., N.Y., 41, 227.

- . (1940). Amer. J. med. Sci., 199, 1.

Rhoads, J. E., and Fliegelman, M. T. (1940). J. Amer. med. Ass., 114, 400.

Roderick, L. M. (1931). Amer. J. Phisiol., 96, 413.

Schonheyder, F. (1936). Biochem. J., 30, 890.

Smith, H. P., Ziffren, S. E., Owen, C. A., and Hoffmann, G. R. (1939). J. Amer. med. Ass., $113,380$.

Snelling, C. E. (1940). Personal communication.

Waddell, W. W., and Guerry, D. (1939). J. Amer. med. Ass., 112, 2259.

- - - Bray, W. E., and Kelley, O. R. (1939). Proc. Soc. exp. Biol., N.Y., 40, 432. 